\title{
Numerical simulation of the neighborhood effects on the wind loading over standard model-scale tall buildings
}

\author{
Simulação numérica do escoamento atmosférico sobre edifícios altos para \\ determinação do efeito de vizinhança
}

\author{
Fernando Oliveira de Andrade' \\ Cristiano Maciel" \\ Roberto Carlos Moro Filho"I' \\ Marcelo Marques ${ }^{\text {IV }}$
}

\begin{abstract}
Numerical simulations of atmospheric flow were carried out in this study in order to evaluate the neighborhood effects on the wind loading over standard model-scale tall buildings. The computational models were developed by solving the steady-state Reynolds Averaged Navier-Stokes equations (RANS equations) with turbulence treated by a $k-\varepsilon$ model. Two building positioning scenarios were simulated: scenario- 1 consisted of the isolated configuration of a standard model-scale building and scenario-2 was composed of the standard building with a selected neighborhood. Both scenarios were analyzed for wind incidence angles of zero, 45, and 90 degrees. The numerical results were obtained in terms of pressure and force coefficients which allowed the determination of neighborhood factors. The simulations showed that the neighborhood influences the mean wind loading on the faces of the standard building, sometimes amplifying the load (in the case of incident winds at zero and 90 degrees), sometimes attenuating the acting forces (in the case of incident winds at zero and 45 degrees). The numerical results were compared with experimental data and showed similar orders of magnitude suggesting that the simulations correctly describe the physical behavior of the wind action.
\end{abstract}

Keywords: Numerical simulation of atmospheric flow; Numerical simulation of tall buildings; Neighborhood effects.

\section{Resumo}

Nesse trabalho foram realizadas simulações numéricas do escoamento atmosférico com o principal objetivo de avaliar os efeitos de vizinhança em edifícios altos. Os modelos computacionais foram desenvolvidos mediante o uso do método RANS, sendo o fechamento da turbulência tratado por um modelo do tipo k- $\varepsilon$. Foram simulados dois cenários de posicionamento de edifícios: o cenário-1 consistiu na configuração isolada de um edifício padrão e o cenário-2 foi composto pelo edifício padrão com uma vizinhança selecionada. Ambos os cenários foram analisados para ângulos de incidência de ventos de zero, 45 e 90 graus. Os resultados numéricos foram obtidos em termos de coeficientes de pressão e força, os quais permitiram a determinação dos fatores de vizinhança. As simulações mostraram que a vizinhança influencia de forma significativa a atuação do vento sobre as fachadas do edifício padrão, ora amplificando o carregamento, ora atenuando as forças atuantes. Os resultados numéricos foram comparados com experimentos e mostraram ordens de

\footnotetext{
'Federal University of Technology Paraná, Curitiba, PR, Brazil - fandrade@utfpr.edu.br.

"Federal University of Technology Paraná, Curitiba, PR, Brazil - cristianomaciel@alunos.utfpr.edu.br.

III Federal University of Technology Paraná, Curitiba, PR, Brazil - robertoc@utfpr.edu.br.

Iv State University of Maringá, Maringá, PR, Brazil - mmarques@uem.br.
} 
grandeza semelhantes, sugerindo que as simulações descrevem de forma adequada o comportamento físico da ação dos ventos.

Palavras-Chave: Escoamento atmosférico; Simulação numérica de edifícios altos; Efeitos de vizinhança.

\section{Introduction}

In the last decades, the massive urbanization due to rural exodus across the planet has resulted in urban verticalization. Large urban centers accumulate resources which encourages the development of the real estate market and favors the construction of taller buildings in a denser configuration. The density and positioning of neighbor buildings can sometimes modify the characteristics of atmospheric flow and wind loadings (Brito et al., 2018).

Major changes in the distribution of atmospheric flow and the consequent wind action on structures have been observed since the 1930s. Blessman (1985) reported that the Empire State building in the United States would have twice as much torsional loading in the existence of a neighborhood of prismatic buildings positioned upstream. Laboratory tests have demonstrated that the density and positioning of upstream obstacles would impact the structural design of the building and also modify the distribution of atmospheric flow in the surroundings.

In Brazil, the discussion on the implications of the action of atmospheric flow on buildings is dealt with the standard NBR 6123 (ABNT, 1988), with the objective of establishing minimum conditions required in the analysis of the forces resulting from static and dynamic actions of the wind that act in buildings considered to be standard. The concept of neighborhood effect is addressed by the Brazilian standard and is defined by the comparison of aerodynamic coefficients (for example, force coefficients), obtained with the configuration of isolated buildings and in the presence of neighboring buildings (Luiza et al., 2019). The neighborhood factor is greater than the unit in the case where the neighborhood amplifies the wind force on the structures and less than the unit if the neighborhood attenuates the forces resulting from the atmospheric flow. In addition to the use of the standard, the impacts of atmospheric flow on buildings can be studied using 
experimental or numerical techniques. The experimental studies are based on reduced-scale laboratory models, making use of wind tunnels and equipment for measuring velocity, force, and pressure (Zhang and Li, 2017). Numerical studies are developed on computers which allow the solution of conservation equations for the quantities of interest using numerical methods (Bowen, 2015, Marques and Andrade, 2017).

In general, the experimental approach tends to be relatively expensive since it requires a complex infrastructure for the physical development of the scale model. Furthermore, experiments may also require sophisticated measurement equipment such as PIV (Particle Image Velocimetry) or LDA (Doppler Effect Anemometer) (Hui et al., 2013). For this reason and also due to the current stage of the evolution of computers, the numerical approach has been widely used in recent years.

Zhang and Gu (2008) performed numerical simulations of the aerodynamic behavior on a standard CAARC building (Melbourne, 1980) and its neighborhood, using the RANS formulation (Reynolds Average Navier-Stokes) with a k- $-\varepsilon$ turbulence model. This approach allowed obtaining mean values of flow velocity, force coefficients, and pressure on the structure of the standard building. The results were compared with experimental data and both demonstrated that the neighborhood factor varied significantly amplifying or attenuating the distribution of forces on the buildings depending on the angle of incidence of average winds.

Tamura (2008), Dagnew et al. (2010) and Elshaer et al. (2016) performed simulations using the Large Eddy Simulation (LES) method using the standard building in isolation and in a high-density neighborhood configuration. Values for pressure coefficients distribution around the buildings were obtained and the influence of the positioning of the buildings on the distribution of atmospheric flow was also evaluated, in terms of the average velocity and the characteristics of turbulence. Validation procedures for numerical models were performed, obtaining satisfactory levels of agreement between the results obtained in the simulations with experimentally measured data. These studies concluded that numerical simulations are a viable alternative for a wide range of wind engineering applications. 
In this study, numerical simulations of wind flow around standard model-scale CAARC buildings were developed, where the buildings were positioned in isolation and with a neighborhood configuration, considering three wind incidence angles. The simulations were performed using the RANS method with a $k-\varepsilon$ turbulence model. The boundary conditions and geometric configurations of both isolated and neighborhood scenarios were based on the experimental work of Fontoura (2014). The numerical results were obtained in terms of pressure coefficient distribution on the four faces of the standard building and force coefficients in the longitudinal and transversal directions of the standard building. The neighborhood factor was obtained for each scenario in order to allow an assessment of the influence of the selected neighborhood as a function of the predominant wind direction. Finally, the numerical results were compared with the data measured in a wind tunnel by Fontoura (2014).

\section{Materials and Methods}

\subsection{Mathematical formulation}

In this study, the evolution of the flow is described by the steady-state mass and momentum conservation equations for a Newtonian and incompressible fluid. Applying the Reynolds decomposition and extracting the time average of the conservation equations, the so-called Navier-Stokes average equations (RANS) are obtained. This process results in the appearance of the Reynolds stress tensor that needs to be modeled (Pope, 2000). The turbulent viscosity approach was adopted for modeling the Reynolds stress tensor (Lesieur, 1990), so the final equations in Cartesian coordinates are written as the following, with i and $\mathrm{j}=1,2$, and 3 :

$$
\begin{aligned}
& \frac{\partial \bar{u}_{\imath}}{\partial x_{i}}=0 \\
& \frac{\partial \rho \bar{u}_{\imath} \bar{u}_{j}}{\partial x_{j}}=-\frac{\partial \bar{p}}{\partial x_{i}}+\frac{\partial}{\partial x_{j}}\left[\left(\mu+\mu_{T}\right)\left(\frac{\partial \bar{u}_{l}}{\partial x_{j}}+\frac{\partial \bar{u}_{j}}{\partial x_{i}}\right)\right]+\rho g_{i},
\end{aligned}
$$


where $u_{i}$ and $u_{j}$ are the velocity vector components, $p$ is the pressure, $\mu$ is the molecular viscosity, $g$ is the gravity and, $\mu_{\top}$ is the turbulent viscosity.

In this study, the k- $\varepsilon$ model (Launder and Spalding, 1974) with standard wall function was adopted, which calculates the turbulent viscosity based on characteristic velocity and length scales as follows:

$$
\mu_{T}=C_{\mu} \rho \frac{k^{2}}{\varepsilon}
$$

where $\mathrm{k}$ is the turbulent kinetic energy (characteristic velocity scale), $\varepsilon$ is the turbulent kinetic energy dissipation rate (characteristic length scale) and $C_{\mu}=0.09$ is an empirical constant. Two transport equations are solved, one for $k$ and one for $\varepsilon$, which are written respectively as follows:

$$
\begin{aligned}
& \frac{\partial \rho k}{\partial t}+\frac{\partial \rho \overline{u_{j}} k}{\partial x_{j}}=P-\rho \varepsilon+\frac{\partial}{\partial x_{i}}\left[\left(\mu+\frac{\mu_{T}}{\sigma_{k}}\right) \frac{\partial k}{\partial x_{i}}\right], \\
& \frac{\partial \rho \varepsilon}{\partial t}+\frac{\partial \rho \bar{u}_{j} \varepsilon}{\partial x_{j}}=C_{\varepsilon 1} \frac{\varepsilon}{k} P-C_{\varepsilon 2} \rho \frac{\varepsilon^{2}}{k}+\frac{\partial}{\partial x_{i}}\left[\left(\mu+\frac{\mu_{T}}{\sigma_{\varepsilon}}\right) \frac{\partial \varepsilon}{\partial x_{i}}\right],
\end{aligned}
$$

where $P$ is the production term given by:

$$
P=\mu_{T}\left[\left(\frac{\partial \overline{u_{l}}}{\partial x_{j}}+\frac{\partial \overline{u_{j}}}{\partial x_{i}}\right) \frac{\partial \overline{u_{l}}}{\partial x_{j}}-\frac{2}{3}\left(\frac{\partial \overline{u_{m}}}{\partial x_{m}}\right)^{2}\right]-\frac{2}{3} \rho k\left(\frac{\partial \overline{u_{n}}}{\partial x_{n}}\right)
$$

where $C \varepsilon 1=1.44, C \varepsilon 2=1.92, \sigma \mathrm{k}=1.0$, and $\sigma \varepsilon=1.3$ the other empirical constants in the model. Equations (1), (2), (4), and (5) are solved simultaneously to obtain the velocity and pressure fields in steady state condition.

\subsection{Numerical methods}

The computational fluid dynamics software Ansys Fluent was employed in this work, which uses the finite volume method for the numerical solution of the governing equations (Patankar, 1980). The spatial domain was discretized using uniformly distributed control volumes and gradients and divergences were discretized using second order resolution upwind schemes. The pressure - velocity coupling was obtained using the SIMPLE method. 
Due to the mesh size limitation of the student software license used in this work and also due to limitations on computational power available for processing, all meshes were sized with less than 400 thousand control volumes to allow for timely simulations on a personal computer with an Intel i7 processor and 8 GB of RAM. In this context, no mesh sensitivity analyzes were performed. Therefore, it is possible that more refined meshes would produce distinct outputs and maybe perform in different ways with regard to the experimental observations. For the meshes used in this work, on the wall surfaces and buildings faces the values of $\mathrm{y}^{+}$ranged from approximately 250 to 1200 .

\subsection{Aerodynamic coefficients}

The numerical solution of the flow provided the mean pressure and velocity distributions. Based on these values, the aerodynamic coefficients of practical interest for this study were possible to calculate, the first being the pressure coefficient that can be written as:

$$
C_{p}=\frac{p-p_{0}}{\frac{1}{2} \rho V_{\infty}^{2}},
$$

here $C_{p}$ is the pressure coefficient, $p$ is the local pressure value, $p_{0}$ is a reference pressure adopted as being the atmospheric pressure and $\mathrm{V}_{\infty}$ is a reference velocity, adopted as being equal to the free stream wind velocity.

The force coefficient is a dimensionless parameter that correlates the resulting force in the direction of a predefined axis with the force resulting from the dynamic pressure. The force coefficient is applied for longitudinal and transversal directions and can be calculated as follows:

$$
C_{f}=\frac{F}{\frac{1}{2} \rho V_{\infty}^{2} S_{a}},
$$


where $C_{f}$ is the force coefficient, $F$ is the resulting force acting on the building in the longitudinal $\left(F_{x}\right)$ or transverse $\left(F_{y}\right)$ directions, and $S_{\alpha}$ is the shadow area of the structure in the analyzed direction.

Based on the force coefficient, it was possible to calculate the neighborhood factor by comparing the coefficient obtained for the isolated building in relation to the coefficient of the building with the neighborhood. The neighborhood factor based on the force coefficient is given by:

$$
N F_{F}=\frac{C f_{i}}{C f_{N}}
$$

where $\mathrm{NF}_{\mathrm{F}}$ is the neighborhood factor that provides the comparison of the force coefficient of the isolated building $\left(C_{\mathrm{fi}}\right)$ to the force coefficient with neighborhood $\left(\mathrm{C}_{\mathrm{fN}}\right)$. $A$ neighborhood factor greater than unit indicates increase of wind loading, whereas a neighborhood factor smaller than unit indicates an attenuation of the wind action on the analyzed structure.

\subsection{Simulation scenarios}

The scenarios chosen for the simulations were based on the wind tunnel study of Fontoura (2014). This study used a standard CAARC building that consisted of a $45.75 \mathrm{~m}$ long, $30.48 \mathrm{~m}$ wide, and $182.88 \mathrm{~m}$ high solid block. In the laboratory model a geometric scale of 1:406 was adopted, resulting in a standard model building with dimensions of $0.0750 \mathrm{~m} \times 0.1127 \mathrm{~m} \times 0.4504 \mathrm{~m}$.

The standard model building and the neighborhoods were positioned in the wind tunnel measurement chamber in a template, so that the building to be studied was in the center of the template. The numerical simulations were performed for the isolated building and for a selected neighborhood. Figure 1(a) shows the positioning template of the buildings with the selected neighborhood. The studied model building is in the center of the template in dark gray and the neighborhood buildings in light gray. Figure 1(b) shows the standard building cross sections dimensions with the respective face nomenclatures. 
Figure 1 - (a) Positioning template for the standard model building and the neighborhood selected for the simulation scenarios, (b) Face nomenclatures for the analyzed model building

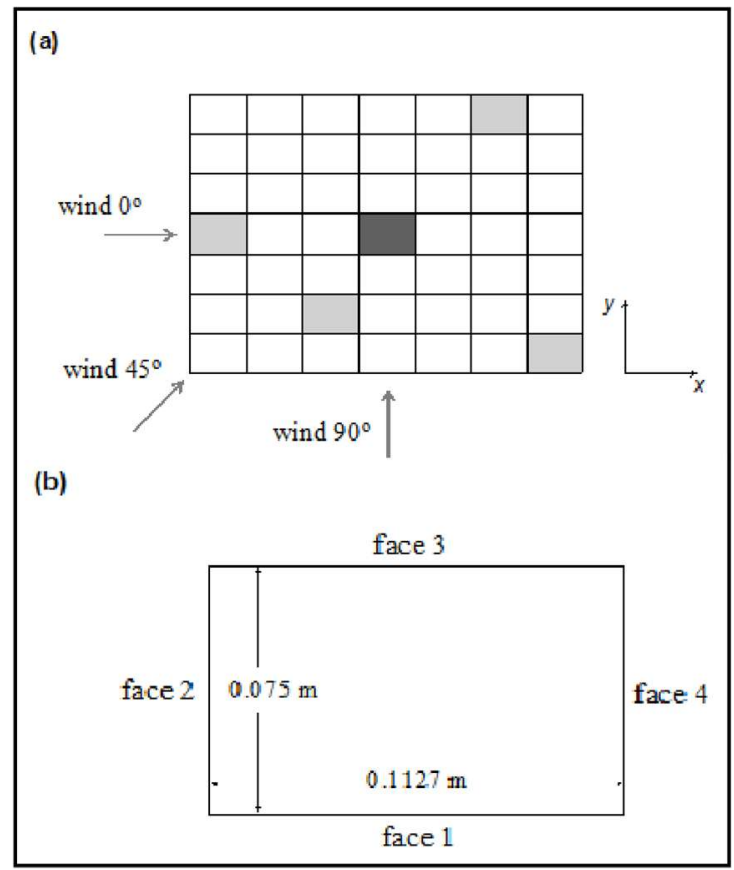

The simulations were performed for wind directions of 0,45 , and 90 degrees. Scenario-1 simulated the isolated standard building and scenario-2 simulated the standard building with the neighborhood illustrated in Figure 1(a). For the scenario-2 the neighborhood buildings have identical dimensions to the standard building. The nomenclature of the facades of the standard building is shown in Figure 1(b) which shows that facade 2 is normal to zero-degree wind and facade 1 is normal to the 90 -degree wind direction. 


\subsection{Boundary conditions and computational meshes}

All simulations were performed using a wind velocity of $40.9 \mathrm{~m} / \mathrm{s}$ uniformly distributed at the entrance to the computational domain. The density of the air was considered constant and equal to $1.20 \mathrm{~kg} / \mathrm{m}^{3}$. The turbulence intensity at the entrance was $10 \%$ and the turbulence characteristic length scale was set to $0.2 \mathrm{~m}$. The computational domain represented a section of the wind tunnel, consisting of a rectangle $5.00 \mathrm{~m}$ long, 1.30 $\mathrm{m}$ wide, and $0.90 \mathrm{~m}$ high.

The Reynolds number calculated based on the height of the wind tunnel resulted in $2.6 \times 10^{6}$. On the sides, walls were adopted without roughness with a non-slip condition. The floor and buildings surfaces were also represented by smooth walls and at the exit an atmospheric pressure condition was adopted. These boundary conditions were identical to those used by Fontoura (2014) and adopted for both simulation scenarios.

\subsubsection{Computational meshes of scenario-1}

The computational meshes used in the scenario-1 simulations were uniform meshes composed of $50 \mathrm{~mm} \times 40 \mathrm{~mm} \times 40 \mathrm{~mm}$ control volumes. Figure 2 shows the computational mesh used in scenario-1 for zero-degree incident wind, displaying the boundaries (entrance, exit, side walls, floor, and standard building) and the dimension of the control volumes on the floor. The flow takes place in the positive direction of the Cartesian $x$-axis and the building was positioned $2 \mathrm{~m}$ from the entrance to the domain.

Figure 2 - Computational mesh used for the isolated model building case for wind with zero degree of incidence, showing the contours and the dimension of the faces of the control volumes on the floor 


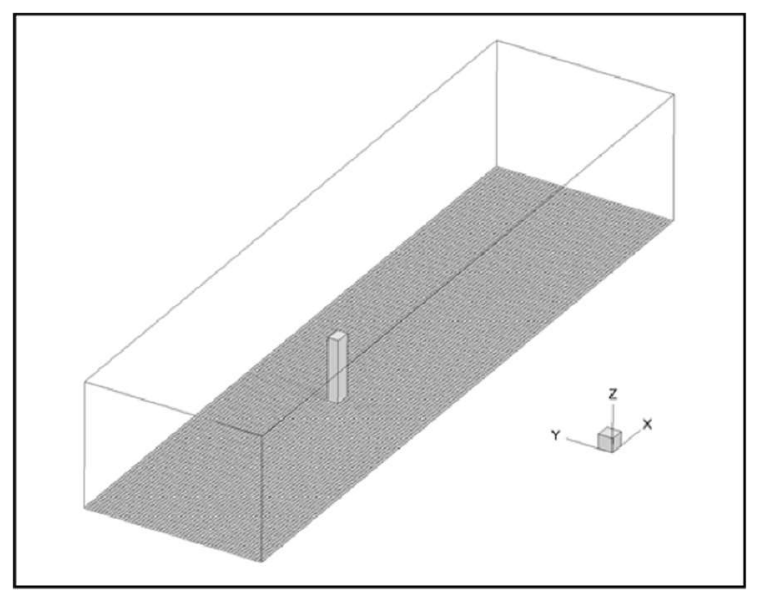

For simulations with wind incidence angles of 45 and 90 degrees, two other meshes with identical dimensions were constructed, so that the model building underwent rotation around its axis in relation to the mesh floor. As a result, the respective incidence angles were equivalent to those simulated by Fontoura (2014).

\subsubsection{Computational meshes of scenario-2}

The computational meshes used in the simulations of scenario- 2 have the same dimensions as scenario-1. The same standard building was used and the neighborhood buildings were similar to the standard. Figure 3 shows the computational mesh used in scenario-2 for zero-degree incident wind, showing the positioning of the standard building with the selected neighborhood.

As in the case of the isolated building, in order to simulate the wind incidence angles of 45 and 90 degrees, two other meshes with similar dimensions were developed, in a way that the set formed by the standard building and neighbor buildings underwent rotation. It is important to emphasize that the entire set of buildings suffered rotation under the same reference point (center of the standard building), so that the relative position between the buildings remained unchanged.

Figure 3 - Computational mesh used for the case of the model building with neighborhood for zero-degree incident wind. The figure shows the positioning of the neighborhood, the contours, and illustratively the dimension of the faces of the control volumes on the floor 


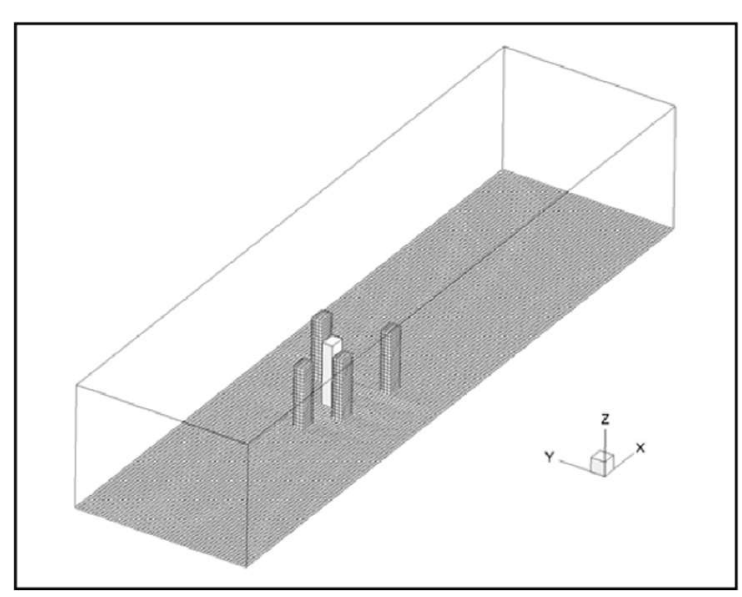

\section{Results and Discussion}

\subsection{Scenario-1: isolated standard building}

The first results obtained in scenario- 1 concern the pressure coefficient, $C_{p}$. A qualitative analysis of the results was carried out through a visual observation of the pressure coefficient distribution on the facades of the standard building. This qualitative analysis was performed only for cases of incident winds of zero and 90 degrees.

Figure $4(a)$ and $4(b)$ shows the distribution of pressure coefficients on the four facades of the standard model building for scenario-1, considering zero and 90-degrees wind incidence angles, respectively. In both cases, the distribution of the pressure coefficient showed to be qualitatively compatible with an expected distribution.

Figure 4(a) shows that for the zero-degree angle of incidence, the highest values of pressure coefficient occur in the center on facade 2 which receives the wind from the front. The same behavior happens for facade 1 , in the case of incident wind at 90 degrees, as shown in figure $4(b)$. In these two cases, the highest values are concentrated in the center of the facades, presenting a gradual reduction towards the edges where the minimum values occur. It is also observed that the lateral facades parallel to the wind directions present symmetrical distributions, as expected. In addition, the facades opposite to the wind directions show negative values of pressure coefficients, which is also expected, since the flow recirculation typically occurs in the downstream regions of the standard building. 
Figure 4 - Distribution of pressure coefficient for the isolated scenario on the four facades of the standard model building: (a) wind incidence of zero-degree, (b) wind incidence of 90-degree

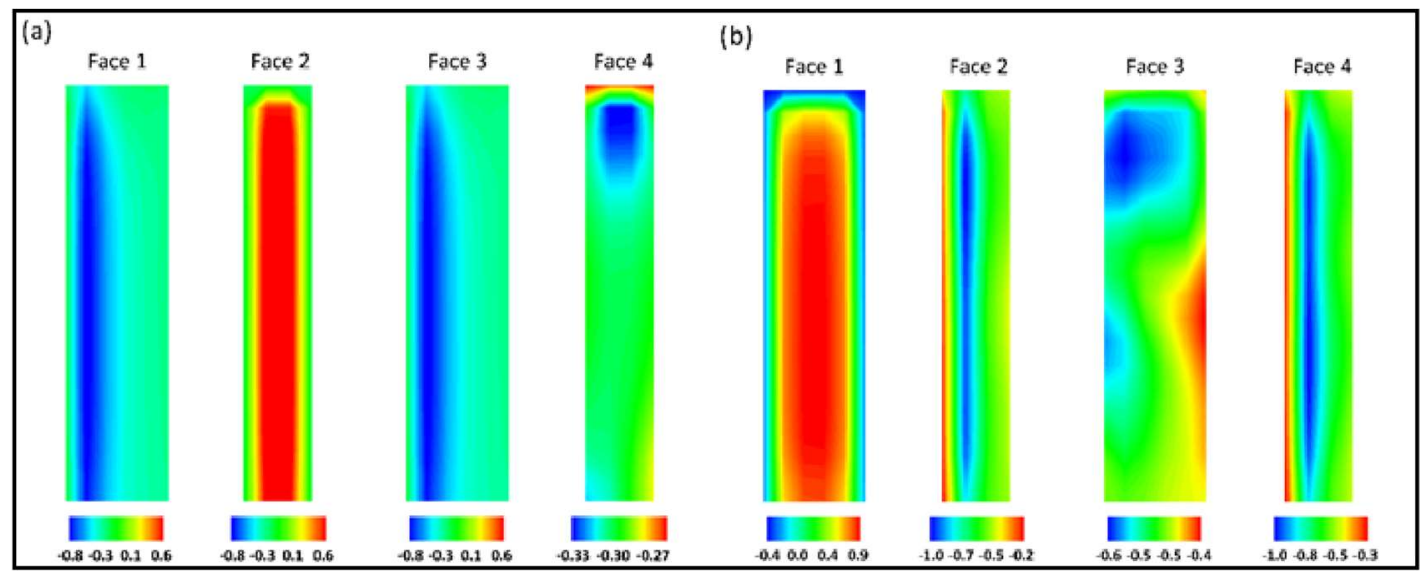

A quantitative analysis of pressure coefficient distribution was performed by comparing the results obtained in the four facades with the data measured in Fontoura (2014). Thirty-five points were selected and distributed uniformly in each of the four facades where the results of the simulations were compared to the measured data.

Since there are a large number of comparison points, only the points of minimum and maximum differences were selected, and the differences were presented in absolute values. Table 1 shows the absolute values of the minimum and maximum differences resulting from the comparison of the simulated and measured pressure coefficients for the 4 facades of the standard building, and for the wind incidence angles of zero, 45, and 90 degrees.

Table 1 - Summary of the results of the pressure coefficients for the four facades of the standard building: comparison of the minimum and maximum differences between the results of the simulations and data obtained by Fontoura (2014)

\begin{tabular}{lcccccc}
\hline & \multicolumn{2}{c}{$\boldsymbol{C} \boldsymbol{p}$ (minimum absolute differences) } & \multicolumn{3}{c}{$\boldsymbol{C} \boldsymbol{p}$ (maximum absolute differences) } \\
\cline { 2 - 6 } & $\mathbf{0}^{\circ}$ & $\mathbf{4 5}^{\circ}$ & $\mathbf{9 0}^{\circ}$ & $\mathbf{0}^{\circ}$ & $\mathbf{4 5}^{\circ}$ & $\mathbf{9 0}^{\circ}$ \\
\hline Facade 1 & 0.01868 & 0.07952 & 0.32287 & 0.54603 & 0.43865 & 0.46287 \\
Facade 2 & 0.00140 & 0.01360 & 0.62732 & 0.31741 & 0.64095 & 0.63459 \\
Facade 3 & 0.01368 & 0.10549 & 0.20970 & 0.56103 & 0.85778 & 0.60232 \\
Facade 4 & 0.06099 & 0.04361 & 0.37140 & 0.24502 & 0.38640 & 0.42515 \\
\hline
\end{tabular}


In general, the results of the simulations showed good agreement with the experimental data for zero-degree wind incidence angle. In this case, the smallest difference between simulated and measured pressure coefficients was 0.00140 for facade 2 and the largest difference was 0.56103 for facade 3. For the 45 -degree wind incidence angle, the smallest difference was 0.01360 for facade 2 and the biggest difference was 0.85778 for facade 3. For the 90-degree wind incidence angle, the smallest difference was 0.20970 for facade 3 and the biggest difference was 0.63459 for the facade 2 . The results in table 1 show that the simulations tend to be more coincident with the experimental data on the facades that are perpendicular to the wind direction (i.e. under direct and frontal wind action).

In order to calculate the force coefficients, the two horizontal flat axes orthogonal to the building height were considered and named $x$ and $y$-axes. The $x$-axis parallel to the facades 2 and 4 and the $y$-axis parallel to the facades 1 and 3, as shown in figure 1 . Therefore, in the case of simulations with a zero-degree wind incidence angle, the wind direction was parallel to the $x$-axis, whereas in simulations with a 90-degree incidence angle the wind direction was considered parallel to the y-axis.

Table 2 - Summary of the force coefficients results in the $\mathrm{x}$ and $\mathrm{y}$ directions for scenario1: comparison between the results of the simulations and experimental measurements by Fontoura (2014)

\begin{tabular}{lcccccc}
\hline & \multicolumn{4}{c}{ Numerical simulations results } & \multicolumn{2}{c}{ Fontoura's experiments (2014) } \\
\hline Cases & $F_{x}(\mathrm{~N})$ & $\mathrm{F}_{\mathrm{y}}(\mathrm{N})$ & $C_{f x}$ & $C_{f y}$ & $C_{f x}$ & $C_{f y}$ \\
Wind at $0^{\circ}$ & 35.25 & 0.03 & 1.02 & 0.001 & 1.00 & 0.01 \\
Wind at $45^{\circ}$ & 69.51 & 3.21 & 0.79 & 0.87 & 0.86 & 0.90 \\
Wind at $90^{\circ}$ & 3.47 & 64.82 & 0.10 & 1.25 & 0.01 & 1.30 \\
\hline
\end{tabular}

The resulting forces calculated in the simulations in the $\mathrm{x}$ and $\mathrm{y}$ directions were determined for the three wind incidence angles. The areas projected by the facades of the buildings in the $\mathrm{x}$ and $\mathrm{y}$ directions were calculated in order to allow the determination of the force coefficients according to equation 8 . The force coefficient in the $x$ direction was called $C_{f x}$ and the resulting force coefficient for the $y$ direction was called $C_{f y}$. Table 2 shows 
the results of the force coefficients $C_{\mathrm{fx}}$ and $\mathrm{C}_{\mathrm{fy}}$ obtained by the simulations and measured in the experiment of Fontoura (2014) for the wind incidence angles of zero, 45, and 90 degrees.

For the cases of zero and 90-degrees incident wind, the coefficients were practically coincident between simulation and experiment, when the wind was received from the front. For the incident wind at 45 degrees the simulated results showed some discrepancies when compared to experiments (absolute diferences of 0,07 for $C_{f x}$ and 0,03 for $C_{f y}$ ). However, the general pattern and order of magnitude of the simulations agreed with the experimental data, confirming that the simulations can describe correctly the physical behavior of the wind action.

3.2 Scenario-2: standard building with the selected neighborhood

In scenario-2, the same coefficients were calculated as in scenario-1, except for the pressure coefficient whose analysis was not developed because there was no experimental data to perform the comparisons. Therefore, only the force coefficients for the $\mathrm{x}$ and $\mathrm{y}$ directions were obtained using equation 8 . Table 3 shows the results of the force coefficients $\mathrm{C}_{\mathrm{fx}}$ and $\mathrm{Cf}_{\mathrm{y}}$ obtained by the simulations and measured by Fontoura (2014) for the case of scenario-2 with the selected neighborhood, and for the wind incidence angles of zero, 45 , and 90 degrees.

Table 3 - Summary of the force coefficients results in the $\mathrm{x}$ and $\mathrm{y}$ directions for scenario2: comparison between the results of the simulations and experimental measurements by

Fontoura (2014)

\begin{tabular}{lcccccc}
\hline & \multicolumn{3}{c}{ Numerical simulations results } & \multicolumn{2}{c}{ Fontoura's experiments (2014) } \\
\hline Cases & $F_{x}(\mathrm{~N})$ & $F_{y}(\mathrm{~N})$ & $C_{f x}$ & $C_{f y}$ & $C_{f x}$ & $C_{f y}$ \\
Wind at $0^{\circ}$ & 18.34 & 0.10 & 0.53 & 0.002 & 0.55 & 0.20 \\
Wind at $45^{\circ}$ & 6.14 & 7.90 & 0.02 & 0.17 & 0.02 & 0.07 \\
Wind at $90^{\circ}$ & 11.51 & 97.39 & 0.33 & 1.88 & 0.11 & 1.46 \\
\hline
\end{tabular}

Based on these force coefficients, the neighborhood factors were obtained through equation 9. The neighborhood factors were determined based on the force coefficient in the $\mathrm{x}$ direction, called $\mathrm{NF}_{\mathrm{Fx}_{\mathrm{x}}}$ and the neighborhood factor based on the force coefficient in the $y$ direction, called NFFy. Table 4 shows the results of the neighborhood factors $N F_{F x}$ and 
$\mathrm{NF}_{\mathrm{Fy}}$ obtained by the simulations and measured in the Fontoura (2014) for the wind incidence angles of zero, 45, and 90 degrees.

Table 4 - Results of neighborhood factors $\mathrm{NF}_{\mathrm{Fx}}$ and $\mathrm{NF}_{\mathrm{Fy}}$ for scenario-2 with selected neighborhood: comparison between the results of the simulations and experimental measurements by Fontoura (2014)

\begin{tabular}{lcccc}
\hline & \multicolumn{2}{c}{ Numerical simulations results } & \multicolumn{2}{c}{ Fontoura's experiments (2014) } \\
\hline Cases & $N F_{F x}$ & $N F_{F y}$ & $N F_{F x}$ & $N F_{F y}$ \\
Wind at $0^{\circ}$ & 0.52 & 3.43 & 0.55 & 20.00 \\
Wind at $45^{\circ}$ & 0.03 & 0.19 & 0.02 & 0.08 \\
Wind at $90^{\circ}$ & 3.32 & 1.50 & 11.00 & 1.12 \\
\hline
\end{tabular}

In the cases with angle of incidence of zero and 90 degrees, the results of the simulations showed very good agreement with the data measured for the axes of preferred directions. The difference of $\mathrm{NF}_{\mathrm{Fx}}$ values for wind at zero degree was only 0.03 and for $\mathrm{NF}_{\mathrm{Fy}}$ values for wind at 90 degree was 0.38 .

In general, it is possible to observe that the simulated results showed similar patterns to the measured data. However, for the coefficients in oblique incidence angles, the results obtained by the simulations did not fully agree with the experimental data (2014). This may have been due to the fact that the model is not sufficiently refined, therefore, it may not be able to describe the finest interference from neighboring buildings. In addition, there are limitations of the computational method, mesh dimensions, and turbulence model that can be a source of uncertainty, causing inconsistencies when comparing results.

The hypothesis of source of errors due to lack of mesh resolution and imprecision of the turbulence model is presented as the most probable, considering that the results obtained for directions coinciding with the wind incidence direction were closer to the experimental results. This indicates that the model may be failing in regions where there is a strong flow recirculation and, therefore, a high influence of turbulent processes in the flow.

For the zero-degree wind incidence angle, the simulated and measured neighborhood factors $\mathrm{NF}_{\mathrm{Fx}}$ were practically identical at around 0.5 . This value indicates that 
the neighborhood presence reduces the wind force action in the $x$ direction by $50 \%$. In the $y$ direction, the simulated neighborhood factor resulted in 3.43 and the experimentally measured factor in 20, indicating that the influence of the neighborhood was much more prominent in the experimental analysis. In both cases, the presence of neighborhood amplifies the wind load in the y-direction.

For the 45 degree wind incidence angle, the simulated and measured neighborhood factors were all smaller than the unit, indicating that the neighborhood protects the model building from the action of the winds. For the 90-degree wind incidence, the simulated and measured $\mathrm{NF}_{\mathrm{Fy}}$ resulted from 1.12 to 1.5 . These values indicate that the disposition of the neighborhood can amplify the wind loading on the model building in that direction by up to $50 \%$. In the $\mathrm{x}$-direction, the $\mathrm{NF}_{\mathrm{Fx}}$ were between 3.32 and 11 , indicating that the influence of the neighborhood was more pronounced in amplifying the wind load.

\section{Conclusions}

This study aimed to conceive a computational fluid dynamics model for numerical simulation of neighborhood effects on the wind loading over a model-scale standard building. Models were developed using the RANS method that solves steady-state average Navier-Stokes equations using a $k-\varepsilon$ turbulence model. The computational mesh was based on the geometry of Fontoura wind tunnel experiment (2014), so that the simulations adopted the same geometric and boundary conditions for the case of isolated standard building and with a selected neighborhood for wind incidence angles at zero, 45, and 90 degrees.

The results of the simulations were obtained in terms of the pressure coefficient and force coefficients in the $\mathrm{x}$ and $\mathrm{y}$-directions, and the neighborhood factors were calculated based on these last two and compared with the experimental data. The results obtained by the simulations tended to be more coincident with the experimental data in the case of winds acting frontally on the facades of the model building. Both numerical results and experimental data showed that the selected neighborhood has a strong influence on the distribution of atmospheric flow and the consequent effect on the structure of the standard 
building. Neighborhood factors have shown that the neighborhood attenuates the action of the wind (less than unity $\mathrm{NF}_{\mathrm{Fx}}$ at zero-degree and less than unity $\mathrm{NF}_{\mathrm{Fx}}$ and $\mathrm{NF}_{\mathrm{Fy}}$ at 45 degrees) and sometimes amplifies the load on the facades of the standard building (more than unity $\mathrm{NF}_{\mathrm{Fy}}$ at zero-degree and more than unity $\mathrm{NF}_{\mathrm{Fx}}$ and $\mathrm{NF}_{\mathrm{Fx}}$ at 90 degrees).

Furthermore, the numerical results were not fully coincident with the experimental data. The comparisons showed a good coincidence in the cases of frontal wind direction on the facades. Despite the punctual discrepancies, the pattern and order of magnitude of results obtained by the simulations showed good agreement with the experimental measurements, leading to believe that the simulations correctly describe the physical behavior of the winds loadings.

In future studies, it is suggested to develop simulations for other neighborhoods and wind incidence angles. If computational power is feasible, it would be recommended to use much more refined meshes to improve the effectiveness of the treatment of turbulence effects. Finally, an interesting topic would be the analysis of real scale buildings to compare the coefficients found numerically with the coefficients recommended by the Brazilian standard. 


\section{Acknowledgments}

The authors would like to thank the Federal Technological University of Paraná Campus Curitiba - for the support received.

\section{References}

ASSOCIAÇÃO BRASILEIRA DE NORMAS TÉCNICAS. Forças devidas ao vento em edificações. Comitê ABNT/CB-002 Construção Civil. Brasília (Brasil), 1988. 66 p.

BLESSMANN, J. R. Wind excitation of neighbouring tall buildings. Journal of wind engineering and industrial aerodynamics. 1985;18(1);91-103.

BOWEN, Y. Large-eddy simulation of wind effects on a super-tall building in urban environment conditions. Journal of Structure and Infrastructure Engineering. 2015;12(6);765-785.

BRITO, F.; HORTA, C. J. G.; AMARAL, E. F. L. A urbanização recente no Brasil e as aglomerações metropolitanas. Open Science Framework Preprints. 2018 [cited $2018 \mathrm{apr}$ 01]. Available from: https://doi.org/10.31219/osf.io/84b92.

DAGNEW, A. K.; BITSUAMLAK, G. T. LES evaluation of wind pressures on a standard tall building with and without a neighboring building. The Fifth International Symposium on COMPUTATIONAL WIND ENGINEERING (CWE2010). 2010 July 25-28; Chapel Hill North Carolina, USA, 2010.

ELSHAER, A.; HAITHAM, A.; BITSUAMLAKAB, G.; EL DAMATTY, A.; DAGNEW, A. LES evaluation of wind-induced responses for an isolated and a surrounded tall building. Engineering Structures. 2016;115(1);179-195.

FONTOURA, P. C. C. N. Estudo experimental em túnel de vento dos efeitos de vizinhança em edifícios altos. [thesis]. Brasília: Escola de Engenharia/UnB; 2014. 318 p.

HUI, Y.; TAMURA, I.; YOSHIDA, A.; KIKUCHI, H. Pressure and flow field investigation of interference effects on external pressures between high-rise buildings. Journal of Wind Engineering and Industrial Aerodynamics. 2013;115(1);150-161.

LAUNDER, B. E.; SPALDING, D. B. The numerical computation of turbulent flows. Computer Methods in Applied Mechanics and Engineering. 1974;3(2),269-289.

LESIEUR, M. Turbulence in fluids: stochastic and numerical modelling. Springer; 1990. 304 p. 
LUIZA, G. P.; RABACHINIA, G. A.; ARAÚJO, T. S.; MARTINS, G. B.; NADER, G. Estudo do efeito de vizinhança em edificações sujeitas à ação do vento. Revista IPT Tecnologia e Inovação. 2019;2(10);125-136.

MARQUES, M.; ANDRADE, F. O. Automated computation of two-dimensional fetch fields: case study of the Salto Caxias reservoir in southern Brazil. Lake and reservoir management. 2017;33(1); 62-73.

MELBOURNE, W.H. Comparison of measurements on the CAARC standard tall building model in simulated model wind flows. Journal of Wind Engineering and Industrial Aerodynamics. 1980;6(1-2);73-88.

PATANKAR, S. V. Numerical Heat Transfer and Fluid Flow. CRC Press; 1980. 214 p.

POPE, S. B. Turbulent flows. Cambridge University Press; 2000. 806 p.

TAMURA, T. Towards practical use of LES in wind engineering. Journal of Wind Engineering and Industrial Aerodynamics. 2008;96(10-11);1451-1471.

ZHANG, A.; GU, M. Wind tunnel tests and numerical simulations of wind pressures on buildings in staggered arrangement. Journal of Wind Engineering and Industrial Aerodynamics. 2008;96(10-11);2067-2079.

ZHANG, J. W.; LI, Q. S. Wind tunnel test and field measurement study of wind effects on a 600-m-high super-tall building. The Structural Design of Tall and Special Biuldings. 2017;26(17);1385-1398. 